\title{
CRESCIMENTO DE MUDAS MICROPROPAGADAS DE BANANEIRA MICORRIZADAS EM DIFERENTES RECIPIENTES ${ }^{1}$
}

\author{
PATRÍCIA LOPES LEAL 2 , MARCO ANTONIO MARTINS ${ }^{3}$, LUCIANA APARECIDA RODRIGUES ${ }^{4}$, \\ JOLIMAR ANTONIO SCHIAVO
}

\begin{abstract}
RESUMO - Realizou-se um experimento em casa de vegetação, com o objetivo de avaliar a utilização de diferentes recipientes e a eficiência da inoculação com fungo micorrízico arbuscular (FMA), Glomus clarum, no crescimento de mudas micropropagadas de bananeira. O delineamento experimental foi o de blocos casualizados, no esquema fatorial 2x2, sendo 2 tratamentos microbiológicos: Glomus clarum e controle; e 2 recipientes: blocos prensados e tubetes, com 6 repetições. O substrato utilizado para a confecção dos blocos e para o enchimento dos tubetes foi constituído por uma mistura de materiais orgânicos (bagaço de cana + torta de filtro de usina açucareira) e vermiculita. Mudas de bananeira produzidas em blocos prensados e inoculadas com o FMA apresentaram melhores resultados quando comparadas com as produzidas nos tubetes, com incrementos na altura, na produção de matéria seca da parte aérea e no acúmulo de N, P e K de 90\%, 829\%, 2774\%, 249\% e 403\%, respectivamente.
\end{abstract}

Termos para indexação: micorriza arbuscular, Musa sp, micropropagação de mudas, blocos prensados, tubetes plásticos.

\section{GROWTH OF MYCORRHIZAL MICROPROPAGATED BANANA PLANTLETS IN DIFFERENT RECIPIENTS}

ABSTRACT - An experiment under greenhouse was carried out in order to evaluate different recipients and the inoculation with arbuscular mycorrhizal fungus (AMF), Glomus clarum, on the growth of micropropagated banana plantlets. A random block design in a factorial scheme $2 \times 2$ (two microbiological treatments: Glomus clarum and control; two types of recipients: pressed blocks and plastic tubes), with six repetitions, was used. The substrate utilized to construct the pressed blocks and to fill the tubes was constituted by a mixture of organic residue (sugarcane bagasse and filter cake) and vermiculite. Banana plantlets produced in pressed blocks and inoculated with AMF let to better results than their counterparts grown in tubes, increasing the height, shoot dry weight, contents of N, P and K in 90\%, 829\%, 2774\%, $249 \%$ and 403\%, respectively.

Index terms: arbuscular mycorrhizae, Musa sp., plantlets micropropagation, pressed blocks, plastic tubes.

\section{INTRODUÇÃO}

Alguns trabalhos têm demonstrado que a inoculação com fungos micorrízicos arbusculares (FMAs) no sistema de produção de mudas representa um grande potencial, como uma alternativa biológica, para o desenvolvimento de um cultivo racional e eficiente de mudas de diversas fruteiras (Schubert et al., 1990; Jaizme-Vega \& Azcón, 1991; Soares \& Martins, 2000; Martins et al., 2000, Schiavo \& Martins, 2002). A inoculação com FMAs em mudas de bananeira tem proporcionado melhor aclimatação (Yano-Melo et al., 1999), maior resistência ao ataque de nematóides (Jaizme-Vega et al., 1997), maior tolerância ao excesso de $\mathrm{Al}$ (Rufyikiri et al., 2000) e maior crescimento e absorção de nutrientes (Declerk et al., 2002).

As associações micorrízicas arbusculares são caracterizadas por uma simbiose mutualista entre raiz e fungo, sem estado patogênico, que ocorre na maioria das espécies vegetais. Entretanto, devido à natureza biotrófica desses fungos que crescem e se multiplicam somente na presença de raízes metabolicamente ativas, a grande limitação é a produção em escala comercial de inóculo. Metodologias tecnicamente viáveis de inoculação do fungo no hospedeiro também são pouco disponíveis.

Outro fator importante na produção de mudas de boa qualidade é o método de produção. No sistema tradicional, a utilização de recipientes com paredes rígidas, sacolas plásticas ou tubetes, tem demonstrado que esses recipientes, devido ao reduzido volume do substrato e a presença de parede, impõem restrições ao desenvolvimento radicular das mudas, o que provoca, conforme a espécie, estresse e deformações das raízes após plantio (Reis et. al., 1989). Uma alternativa é a produção de mudas no sistema bloco prensado, confeccionado com resíduos orgânicos, cuja vantagem é proporcionar uniformidade do material e condições de homogeneidade no desenvolvimento das mudas. Neste sistema, não há limitações de paredes, proporcionando condições de desenvolvimento de raízes, por todos os lados, sem confinamento ou direcionamento. Espera-se que a produção de mudas de bananeira, nesses blocos, além de permitir a inoculação com FMAs, possa também proporcionar uma uniformidade no desenvolvimento das mudas.

O objetivo deste trabalho foi avaliar diferentes recipientes (tubetes plásticos e blocos prensados) e a eficiência da inoculação com o FMA Glomus clarum na produção de mudas micropropagadas de bananeira.

\section{MATERIALEMÉTODOS}

O experimento foi conduzido em casa de vegetação localizada no câmpus da Universidade Estadual do Norte Fluminense, em Campos dos Goytacazes - RJ.

O delineamento experimental utilizado foi o de blocos casualizados, em esquema fatorial 2x2 (tratamentos microbiológicos: controle ou inoculado com Glomus clarum, e 2 tipos de recipientes: blocos prensados ou tubetes plásticos), com seis repetições, sendo utilizadas seis plantas por repetição.

O substrato utilizado na produção de mudas, nos dois tipos de recipientes, foi constituído por uma mistura de bagaço de cana-de-açúcar, torta de filtro de usina açucareira e vermiculita. Primeiramente, o bagaço de cana e a torta de filtro foram triturados e passados em peneira de $1 \mathrm{~cm}$, misturados na proporção 3/1 (v/v) e , então, colocados para compostar por 35 dias. Após esse período, o material foi misturado com vermiculita na proporção de $3 / 1(\mathrm{v} / \mathrm{v})$ e tratado com brometo de metila, na dose de $30 \mathrm{~cm}^{3} \mathrm{~m}^{-3}$ de substrato, por 48 horas, para eliminação de possíveis patógenos e FMAs nativos. A análise química do substrato revelou os seguintes resultados: $\mathrm{C}=21,36 \% ; \mathrm{N}=1,39 \% ; \mathrm{P}_{2} \mathrm{O}_{5}=1,43 \% ; \mathrm{K}_{2} \mathrm{O}=0,10$ $\% ; \mathrm{Ca}=2,16 \% ; \mathrm{Mg}=0,16 \%$.

Os blocos prensados foram confeccionados com o substrato umedecido, que foi colocado em fôrma metálica com 40x60×20cm (comprimento, largura e altura). Uma tampa foi colocada sobre a fôrma, durante a prensagem, tendo em sua face inferior 96 cones com $1 \mathrm{~cm}$ de altura, destinados a marcar os orifícios a serem plantados. O material foi levado à prensa $\left(10 \mathrm{Kgf} / \mathrm{cm}^{2}\right.$, por $\left.15 \mathrm{~min}\right)$, para agregação do material.

\footnotetext{
${ }^{1}$ (Trabalho 085/2003). Recebido: 16/07/2003. Aceito para publicação: 19/04/2005. Trabalho de Iniciação Científica do primeiro autor. Aceito para publicação em... ${ }^{2}$ Aluna do curso de Ciências Biológicas da UENF/CBB.

${ }^{3}$ Professor do Laboratório de Solos, bolsista do CNPq. UENF/CCTA,. Av. Alberto Lamego, 2000, CEP. 28013-600 Campos dos Goytacazes-RJ. E-mail: marco@ uenf.br. ${ }^{4}$ Pesquisadora do Laboratório de Solos, UENF/CCTA.

${ }^{5}$ Doutorando em Produção Vegetal, UENF/CCTA.
} 
Após esta carga, cada bloco ficou com altura de $10 \mathrm{~cm}$. Em seguida, foram colocados em caixas de madeira, de mesmo comprimento e largura, com fundos telados.

Os tubetes utilizados foram de modelo cônico, com seção circular, contendo oito frisos internos longitudinais e eqüidistantes, com $19 \mathrm{~cm}$ de altura, $5 \mathrm{~cm}$ de diâmetro interno superior e volume de $250 \mathrm{~cm}^{3}$.

A inoculação com o FMA, Glomus clarum Nicolson \& Schenck proveniente da coleção da UENF/Laboratório de Solos, foi feita adicionando-se $10 \%$ de inóculo fúngico ao substrato utilizado para preencher os tubetes ou confeccionar os blocos. $\quad \mathrm{O}$ inóculo fúngico foi produzido seguindo os procedimentos adotados por Schiavo \& Martins (2002).

As plântulas de bananeira (cultivar Prata-Manteiga, subgrupo Figo, grupo genômico AAAB) foram produzidas por micropropagação, seguindo os procedimentos adotados por Samarão et al. (2000).

As plântulas micropropagadas de bananeira foram transferidas para uma cobertura plástica com 50\% de sombreamento, por 15 dias, para aclimatação. Após esse período, uma única plântula enraizada foi plantada em cada célula do bloco ou em cada tubete.

Nos tratamentos com blocos prensados, foram utilizados 12 blocos com dimensões de 60x40 cm, contendo cada bloco 96 células. Assim, em seis blocos prensados, foram plantadas as plântulas de bananeira micorrizadas, e, nos outros seis blocos, as plântulas nãomicorrizadas. No caso dos tratamentos com tubetes, foram utilizadas 12 bandejas com 54 tubetes cada uma, sendo que, em seis delas, foram plantadas as plântulas de bananeira micorrizadas, e nas outras seis as não-micorrizadas. No entanto, o volume de substrato explorado pelas plântulas, em ambos os recipientes, foi o mesmo $\left(250 \mathrm{~cm}^{3}\right)$.

Aos 120 dias após o plantio, seis plantas de cada bloco prensado ou bandeja foram coletadas aleatoriamente, e o sistema radicular foi separado da parte aérea, para a determinação da colonização micorrízica. Após a lavagem com água de torneira, subamostras de $2 \mathrm{~cm}$ de comprimento das raízes foram coletadas e conservadas em etanol a $50 \%$ para posterior determinação da colonização pelo método da interseção em placa de Petri reticulada (Giovannetti \& Mosse, 1980), após a coloração das raízes com azul de metila.

Os teores de N, P, e K, na parte aérea, foram determinados após as amostras terem sido secas em estufa de ventilação forçada, a uma temperatura de aproximadamente $65^{\circ} \mathrm{C}$, por 48 horas (Malavolta et al.,
1989). Após a amostra ser submetida à oxidação pela digestão sulfúrica, o P foi determinado por colorimetria, pelo método do molibdato (Malavolta et al., 1989), o N por método de Nessler (Jackson, 1965) e o K por espectrofotometria de emissão de chama.

Os dados obtidos foram submetidos à análise de variância e as médias comparadas pelo teste de Tukey, a 5\% de probabilidade.

\section{RESULTADOS E DISCUSSÃO}

As mudas de bananeira colonizadas com G. clarum e produzidas nos blocos prensados apresentaram maior altura, produção de matéria seca da parte aérea e acúmulo de N, P e K, quando comparadas com o tratamento-controle $(\mathrm{NI})$, onde se observaram, respectivamente, para estas características, aumentos de 74\%, 218\%, 243\%, 268\% e 41\% (Figura 1). Por outro lado, nas mudas produzidas nos tubetes, a presença do FMAs não proporcionou aumentos significativos nas variáveis analisadas.

As mudas de bananeira produzidas em blocos prensados e inoculadas com o FMA, quando comparadas com as produzidas nos tubetes, apresentaram incrementos na altura, na produção de matéria seca da parte aérea e no acúmulo de N, P e K de 90\%, 829\%, 2774\%, 249\% e $403 \%$, respectivamente (Figura 1 ).

Schiavo \& Martins (2002), estudando o comportamento de mudas de goiabeira produzidas em tubetes ou blocos prensados, também encontraram efeitos positivos da inoculação micorrízica sobre o crescimento e acúmulos de nutrientes, apenas nas mudas produzidas no sistema de blocos prensados. Leles et al. (2000), em experimentos com Eucalyptus camaldulensis, E. grandis e E. pellita, também verificaram que todas estas espécies produzidas em blocos prensados apresentaram valores de altura da parte aérea, diâmetro de colo e área foliar significativamente superiores aos das plantas produzidas em tubetes. De acordo com esses mesmos autores, tais diferenças foram devidas ao maior volume de substrato explorado pelas raízes das mudas de eucaliptos produzidas em blocos prensados em relação aos tubetes, o qual proporcionou aumento da área de absorção de água e nutrientes, uma vez que o volume de substrato explorado pelas raízes, em cada célula do bloco prensado, foi de $250 \mathrm{~cm}^{3}$, e o volume de substrato explorado nos tubetes foi de $50 \mathrm{~cm}^{3}$.

No presente trabalho, na produção de um bloco prensado, foram
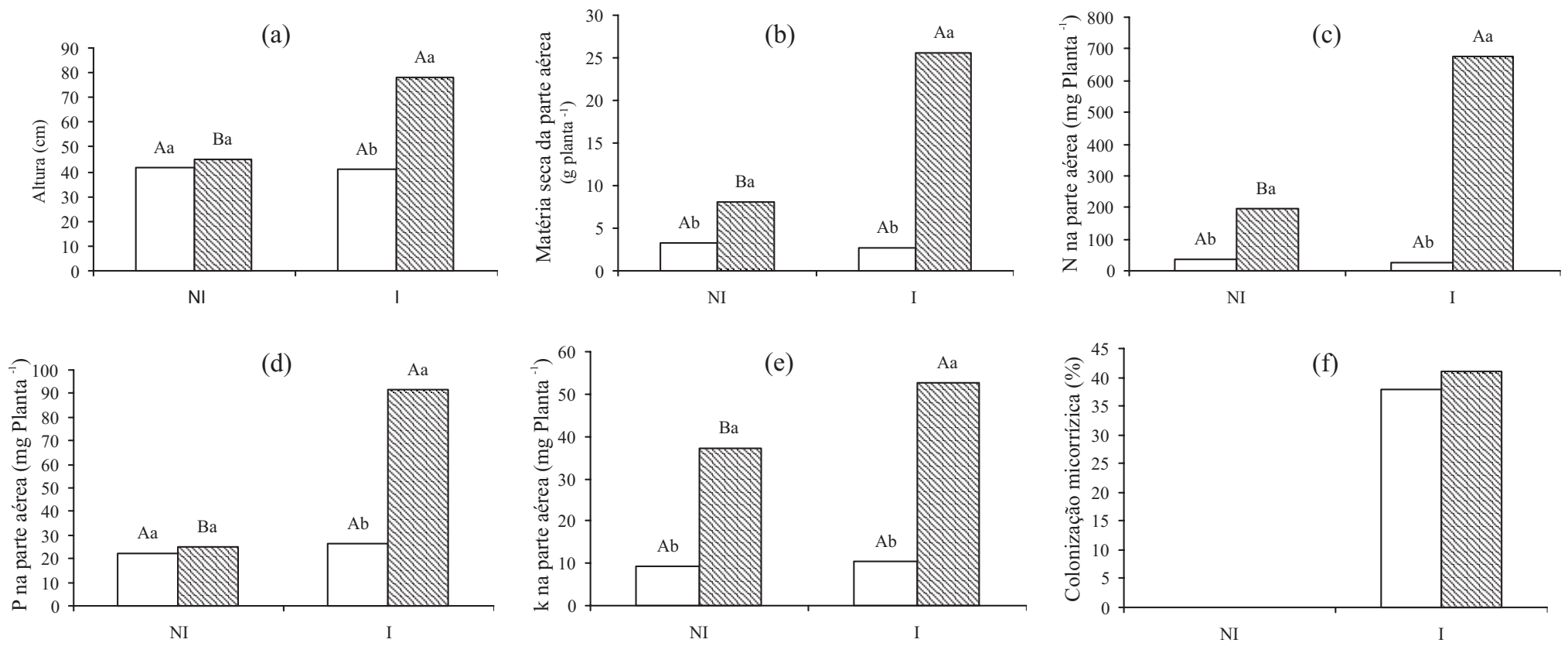

FIGURA 1 - Altura (a); matéria seca (b); conteúdos de N (c), P(d) e K (e) da parte aérea e colonização micorrízica das raízes (f) de mudas de bananeira (Musa sp), inoculadas (I) ou não (NI) com o fungo micorrízico arbuscular Glomus clarum, em tubetes plásticos ( $\square$ ) e em blocos prensados (圈). Médias seguidas pela mesma letra minúscula, para recipiente, e maiúscula para tratamento microbiológico, não diferem entre si, pelo teste de Tukey $(\mathrm{P}<0,05)$. 
usados 36 litros de substrato ( $375 \mathrm{~mL}$ por planta) que, depois de prensado a uma força de $10 \mathrm{kgf} \mathrm{cm}^{-2}$, apresentou o volume de $250 \mathrm{~cm}^{3}$. No caso dos tubetes, houve cuidado de se adicionar $375 \mathrm{~mL}$ de substrato em cada tubete de $250 \mathrm{~cm}^{3}$, para que as plantas nos blocos e nos tubetes pudessem explorar o mesmo volume de substrato. Assim, o menor desenvolvimento das plantas micorrizadas produzidas em tubetes, possivelmente, pode ser atribuído a alterações fisiológicas nas raízes das mudas, reduzindo a absorção de água e nutrientes, causadas pela parede rígida do recipiente, uma vez que a colonização micorrízica foi praticamente igual em ambos os recipientes (Figura 1f). Vários fatores físicos e fisiológicos podem restringir o crescimento radicular e afetar o crescimento, o desenvolvimento e a produtividade das plantas, como a densidade do solo, o tamanho dos agregados e dos poros, a presença de camada compactada subsuperficial, a aeração, a temperatura, a qualidade da luz, as limitações de nutrientes, a densidade de raízes e o volume, tamanho e formato do recipiente onde a planta se desenvolve. No presente trabalho, provavelmente, o formato do recipiente utilizado (tubete $\mathrm{x}$ bloco prensado) foi o principal fator que afetou o desenvolvimento das plantas de bananeira. As plantas produzidas nos tubetes, devido às restrições no crescimento lateral das raízes impostas pelas paredes rígidas, provocam deformações às mesmas por direcionar o seu crescimento para baixo, ao alongo das paredes dos tubetes. Por outro lado, as plantas produzidas nos blocos prensados não sofrem restrições no crescimento lateral de suas raízes e, portanto, ficaram isentas de deformações. Desta forma, provavelmente, essa diferença na arquitetura radicular provocou menor absorção de nutrientes pelas raízes micorrizadas nos tubetes (Figuras 1c, 1d e 1e), a qual refletiu no crescimento da parte aérea das plantas.

Alguns trabalhos realizados para verificar o efeito do volume do recipiente no crescimento e desenvolvimento de plantas têm demonstrado que a restrição radicular pode diminuir o crescimento das raízes e da parte aérea das plantas (Peterson et al., 1991b; Ismail \& Davies, 1998). Na redução do crescimento, podem estar incluídos a inibição da elongação foliar (Peterson et al., 1991a), a fotossíntese (Ismail \& Noor, 1996), a mudança na partição da matéria seca da planta e na absorção de nutrientes (Bar-Tal \& Pressman, 1996) e o metabolismo hormonal (Peterson et al., 1991a, 1991b).

Independentemente do tipo de recipiente utilizado, a inoculação com G. clarum proporcionou aumentos significativos nas variáveis avaliadas. No entanto, as maiores respostas foram verificadas nas mudas produzidas em blocos prensados. Outros autores também têm demonstrado os efeitos benéficos da inoculação com FMAs sobre o crescimento, a aclimatação e a absorção de nutrientes em mudas micropropagadas de bananeiras (Yano-Melo et al., 1999; Declerck et al., 2002).

O principal benefício que os FMAs conferem ao hospedeiro, é o aumento da absorção e da translocação de nutrientes, principalmente os de baixa mobilidade no solo, como o P (Marschner, 1995). Todavia, aumento na absorção de outros nutrientes em plantas micorrizadas, tais como N, K, S, Zn, Cu e Mn, tem sido relatado por outros autores (Marschner e Dell, 1994; Soares \& Martins, 2000). Desta forma, o maior crescimento das mudas de bananeira micorrizadas pode ser atribuído ao maior acúmulo de nutrientes. $\mathrm{O}$ aumento no acúmulo de nutrientes em plantas micorrizadas é atribuído ao aumento na superfície de absorção do sistema radicular conferido pelas hifas externas que crescem vários centímetros além da superfície explorada pelas raízes (Jakobsen et al., 1992), ao aumento no transporte primário de prótons (Bago et al., 1997) e ao aumento na atividade de fosfatases na superfície de raízes (Fries et al., 1998).

Os resultados indicam que a produção de mudas de bananeira em blocos prensados tem como vantagem o maior número de mudas produzidas por área, quando comparado ao sistema de tubetes, além de promover maior desenvolvimento das mudas.

\section{CONCLUSÕES}

1. Os blocos prensados são mais eficientes no crescimento de mudas micropropagadas de bananeiras, em comparação com os tubetes.

2. A espécie Glomus clarum aumenta o crescimento e o acúmulo de nutrientes das mudas de bananeira.

\section{AGRADECIMENTOS}

À Fundação Carlos Chagas Filho de Amparo à Pesquisa do Estado do Rio de Janeiro (FAPERJ), pelo apoio financeiro.

\section{REFERÊNCIAS}

BAGO, B.; DONAIRE, J.P.; AZCÓN-AGUILAR, C. ATPases activities of root from mycorrhizal sunflower (Helianthus annuus) and onion (Allium cepa) plants. New Phytologist, Cambridge, v. 136, p. 305311, 1997.

BAR-TAL, A.; PRESSMAN, E. Root restriction and potassium and calcium solution concentrations affect dry-matter production, cation up-take, and blossom-end rot in greenhouse tomato. Journal of the American Society for Horticultural Science, Alexandria, v. 121, p. 649-655, 1996.

DECLERCK, S; RISEDE, J.M.; DELVAUX, B. Greenhouse responce of micropropagated bananas inoculated with in vitro monoxenically produced arbuscular mycorrhizal fungi. Scientiae Horticulturae, Amsterdam, v. 93, p. 301-309, 2002.

FRIES, L.L.M.; PACOVSKY, R.S.; SAFIR, G.R.; KAMINSKI, J. Phosphorus effect on phosphatase activity in endomycorrhizal maize. Physiology Plantarum, Copenhagen, v. 103, p. 162-171, 1998.

GIOVANNETTI, M.; MOSSE, B. An evaluation of techniques for measuring vesicular-arbuscular mycorrhizal infection in roots. New Phytologist, Cambridge, v. 84, p. 489-500, 1980.

ISMAIL, M.R.; DAVIES, W.J. Root restriction affects leaf growth and stomatal response: the role of xylem sap ABA. Scientiae Horticulturae, Amsterdam, v. 74, p. 257-268, 1998.

ISMAIL, M.R.; K.M. NOOR. Growth, water relations and physiological processes of starfruit (Averrhoa carambola L.) plants under root growth restriction. Scientia Horticulturae, Amsterdan, v. 66, p. 51$58,1996$.

JACKSON, M. L. Soil chemical analysis. New Jersey: Prentice Hall, $1965.489 \mathrm{p}$

JAIZME-VEGA, M.C.; TENOURY, P.; PINOCHET, J.; JAUMOT, M. Interactions between the root-knot nematode Meloidogyne incognita and Glomus mosseae in banana. Plant and Soil, Dordrecht, v.196, p. 27-35, 1997.

JAIZME-VEGA, M.C.J.; AZCÓN, R. Effect of vesicular-arbuscular mycorrhizal fungi on pineapple [Ananas comosus (L.) Merr.] in the Canary Islands. Fruits, Paris, v. 46, p. 47-50, 1991.

JAKOBSEN, I.; ABBOTT, L.K.; ROBSON, A.D. External hyphae of vesicular-arbuscular mycorrhizal fungi associate with Trifolium subterraneum L. I. Spread of hyphae and phosphorus inflow into roots. New Phytologist, Cambridge, v. 120, p. 371-380, 1992.

LELES, P.S.S.; CARNEIRO, J.G. de A.; BARROSO, D.Q.; MORGADO, I.F. Qualidade de mudas de Eucalyptus spp. produzidas em blocos prensados e em tubetes. Revista Árvore, Viçosa, v.24, p.13-20, 2000.

MALAVOLTA, E.; VITTI, G.C.; OLIVEIRA, S.A. Avaliação do estado nutricional das plantas. Piracicaba: Associação Brasileira para Pesquisa da Potassa e do Fosfato, 1989. 201 p.

MARSCHNER, H. Mineral nutrition of higher plants. London: Academic Press, 1995. 889p.

MARSCHNER, H.; DELL, B. Nutrient uptake in mycorrhizal symbiosis. 
Plant and Soil, Dordrecht, v. 159, p. 89-102, 1994.

MARTINS, M.A.; GONÇALVES, G.F.; SOARES, A.C.F. Efeito de fungos micorrízicos arbusculares associados a compostos fenólicos, no crescimento de mudas de mamoeiro. Pesquisa Agropecuária Brasileira, Brasília, v. 35, p. 1465-1471, 2000.

MURASHIGE, T. e SKOOG, F. A revised medium for rapid growth and bioassay with tobacco tissue cultures. Physiology Plantarum, Copenhagen, v. 15, p. 473-497, 1962.

PETERSON, T.A.; COHEN, J.D.; BUTA, J.G.; KRIZEK, D.T. Influence of root restriction on tomato: Changes in leaf cell expansion, abscisic acid and indole-3-acetic acid. Plant Physiology, Rockville, v. 96, p. 78, 1991a. Supplement.

PETERSON, T.A.; REINSEL, M.D.; KRIZEK, D.T. Tomato (Lycopersicum esculentum Mill., cv. 'Better Bush') plant response to root restriction. Journal of Experimental Botany, Oxford, v.42, p.1233-1240, $1991 \mathrm{~b}$.

REIS, G.G.; REIS, M.G.F.; MAESTRI, M.; XAVIER, A.; OLIVEIRA, L.M. Crescimento de Eucaliptus camaldulensis, E. grandis e E. cloeziana sob diferentes níveis de restrição radicular. Revista Árvore, Viçosa, v.13, p.1-18, 1989.

RUFYIKIRI, G.; DECLERCK, S.; DUFEY, J.E.; DELVAX, B. Arbuscular mycorrhizal fungi might alleviate aluminium toxity in banana plants. New Phytologist, Cambridge, v. 148, p. 343-352, 2000.
SAMARÃO, S.S.; MARTINS, M.A.; TEIXEIRA, S.L. Produção de mudas micropropagadas de bananeira (Musa spp) inoculadas com fungos micorrízicos arbusculares. Revista Brasileira de Fruticultura, Jaboticabal, v.22, p.200-204, 2000.

SCHIAVO, J.A.; MARTINS, M..A. Produção de mudas de goiabeira (Psidium guajava L.), inoculadas com o fungo micorrízico arbuscular Glomus clarum, em substrato agroindustrial. Revista Brasileira de Fruticultura, Jaboticabal, v. 24, p. 519-523, 2002.

SCHUBERT, A.; MAZZITELLI, M.; ARIUSSO, O. Effects of vesiculararbuscular mycorrhizal fungi on micropropagated grapevines: Influence of endophyte strain, P fertilization and growth medium. Vitis, Sielbeldiengen, v. 29, p. 5-13, 1990.

SOARES, A.C.F.; MARTINS, M.A. Influência de fungos micorrízicos arbusculares, associada à adição de compostos fenólicos, no crescimento de mudas de maracujazeiro-amarelo (Passiflora edulis f. flavicarpa). Revista Brasileira de Ciência do Solo, Viçosa, v. 24, p. 731-740, 2000.

YANO-MELO, A.M.; SAGGIN, O.J.; LIMA, J.M.; MELO, N.F.; MAIA, L.C. Effect of arbuscular mycorrhizal fungi on the acclimatization of micropropagated banana plantlets. Mycorrhiza, Berlin, v. 9, p. 119$123,1999$. 